\title{
The Technology Research Status and Development Trend of Battery Rubber-tired Vehicle for Coal Mine
}

\author{
Huang Lei ${ }^{1,2}$, Guo-ying Meng ${ }^{1}$ \\ ${ }^{1}$ China University of Mining\& Technology, Beijing, 100083, China \\ ${ }^{2}$ CCTEG Taiyuan Research Institute, Taiyuan, 030006, China
}

Keywords: coal mine, flameproof diesel vehicle, battery rubber-tired vehicle, research status, development trend.

\begin{abstract}
The paper analyses the existing problems of the flameproof diesel vehicle and states battery rubber-tired vehicle will be a development trend in the future. The research status and development trend of the key technologies of battery rubber-tired vehicle are illustrated, and battery vehicle will become the main trackless auxiliary transportation vehicle for green mine.
\end{abstract}

\section{Introduction}

During the period of China's “11th five-year plan”, trackless auxiliary transportation vehicles for coal mine, powered by explosion-proof diesel engine have got rapid development. The diesel engine power was developed from dozens of $\mathrm{kW}$ to $200 \mathrm{~kW}$ or more, the vehicle carrying capacity are raised from several tons to dozens of tons. At present, the world's largest longwall chock carrier (80T) has been developed. Vehicle types include materials-truck, man-truck, engineering materials truck, frame longwall chock carrier, shovel longwall chock carrier, multi-function scooptram, etc. Application range covers personnel transportation, lightweight, middleweight and heavyweight materials and equipments transportation. Application of the above research results of coal mine raises production efficiency, improves coal mine safety, reduces accidents.

Although the diesel engine trackless auxiliary transportation vehicles have many advantages: convenient mobilization, fast speed, high efficiency, long usage range and so on, many deficiencies are exposed in the process of application. On the one hand, the vehicles are powered by diesel oil which belongs to the non-renewable resource, energy consumption is large. The clean and renewable energy vehicles are urgent need under energy increasingly scarce and national policy. On the other hand, in the coal mine narrow roadway, ventilation under the condition of limited, explosion-proof diesel engine emissions such as CO, NOX and vehicle noise will cause serious pollution to the coal mine environment and do harm to underground staff's physical and mental health. Underground trackless auxiliary transportation battery vehicles for coal mine (hereinafter referred to as the underground battery vehicles), whose power can be made by renewable clean energy such as wind, water, and solar energy conversion, do not produce harmful gases such as CO, NOX, basic zero pollution in the underground environment. Therefore, in order to effectively improve the underground working environment, to achieve energy conservation and emissions reduction, underground battery vehicles will become the future development trend of the coal mine underground trackless auxiliary transportation's technology and equipment.

\section{Foreign underground battery vehicle research status}

Since the end of the twentieth century, the underground battery vehicle was researched in abroad, mainly including lightweight underground batter vehicles and heavyweight underground battery engineering vehicles. Lightweight underground batter vehicles manufactured by Johnson and Damascus contain lightweight man-truck and materials-truck. This type of truck uses battery and AC frequency conversion motor technology. Heavyweight underground battery engineering vehicles manufactured by Caterpillar contain 488 flameproof battery forklift truck, VTC6363 type, VTC650 type, VTC680 type. This type of truck use explosion-proof special type lead-acid battery device and the DC motor speed control technology. Explosion-proof battery forklift truck is mainly 
used for float coal cleaning in the underground roadway, transportation of equipment and material, etc. Explosion-proof battery shovel plate bracket truck is mainly used in the transportation of the longwall chock and other equipment and materials.

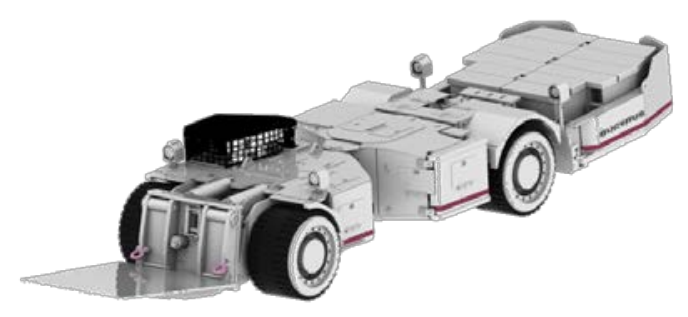

Fig1: VT680 type battery vehicle

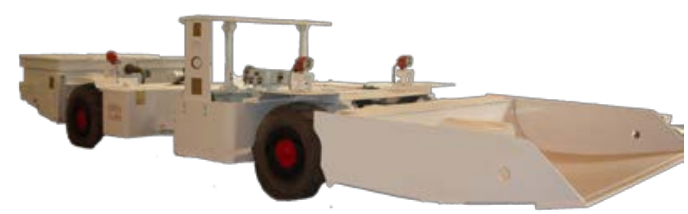

Fig2: Domestic CLX3 battery vehicle

\section{Domestic underground battery vehicle research status}

Domestic underground battery vehicle research started laterly. CCTEG Taiyuan Research Institute began to study this vehicle since 2005, was the earliest study unit in China. CCTEG Taiyuan Research Institute developed the first domestic battery forklift truck in 2009. The vehicle powered by high-capacity lead-acid battery adopted DC chopper speed regulation system. Prototype vehicle had completed the test in Hala-gou coal mine. The results showed that the vehicle basic performance reached the abroad technical level. It marked that our country had made breakthrough progress in the field of underground battery vehicle. At present, CCTEG Taiyuan Research Institute has started to study shovel plate battery vehicle. The vehicle chosen for lead-acid battery as the power source, adopt the imported AC motor and frequency converter speed. The future is expected to replace imported underground battery vehicle as first choice in the case of fast moving working system for coal enterprises. Due to domestic large capacity lithium iron phosphate battery application was still in the stage of exploration in the coal mine, underground battery vehicle powered by lithium iron phosphate was researched. So now for underground lithium iron phosphate battery vehicle research is limited to experimental science, in the future development of lithium iron phosphate battery vehicles to provide scientific basis.

In short, due to domestic in the storage battery charging \& discharging and motor speed control, the core technology research is not mature enough, storage battery, motor and controller and other main components are basically rely on imports. Imported components whose purchasing cycle is long, price is high, after-sales service is not timely, safety standard bidding procedures is complex, seriously restricted the underground battery vehicle research. At present, the underground battery vehicles mainly introduced imported products.

\section{Battery Technology}

Underground battery vehicle as part of the electric drive vehicle is powered by explosion-proof battery. The vehicle's basic transmission principle: battery-motor-reducer-drive axle-tires, so explosion proof electrical system the most important technology in the underground battery. Battery technology and motor driver technology are the most key technology in the explosion proof.

There are two main kinds battery power for underground vehicle: lead-acid battery and lithium iron phosphate. 
Lead-acid battery technology.Lead-acid battery has the following advantages. Slight damage caused by the overcharge and over discharge can be recovered by small current charging. It does not need complex battery management control system. The shortage of the lead-acid battery is big volume and heavy quality, which seriously restrict the range and speed of the vehicle. There will be hydrogen discharge during battery charging and discharging process. Especially in the late charge much distilled water is electrolyzed and a large amount of hydrogen gas is released, which will pollute the coal mine environment. Meanwhile the lead-acid battery will cause serious soil and water pollution, and do harm to human survival environment. Because of the lead-acid battery problems such as hydrogen evolution and electrolyte leakage, "GB3836.2-2010 explosive environment Part 2: the fame-proof shell "d" protection equipment" explicitly states that battery with danger of hydrogen evolution is banned to be enclosed by explosion- proof box. The standard means lead-acid battery used to underground battery vehicles is limited to a certain extent.

At present, 1400Ah is the biggest monomer capacity of special type lead-acid battery which is accredited by China national safety standards. Abroad applied in underground battery vehicle is 2000 Ah. The CLX3 type underground battery forklift vehicle, independently researched and developed by our country, choses domestic $935 \mathrm{Ah}, 132 \mathrm{v}$ battery. The battery vehicles imported by Shendong Coal Corp., such as 488 forklift, VT636, VTC650 are all powered by imported 128v voltage lead-acid battery. In the process of using the vehicle, there will be a problem with the battery voltage level is low, motor calorific value. VCT680 underground battery vehicle was powered by imported 1820Ah, 240V lead-acid battery, electric motor heating is improved obviously.

The current domestic mine high-capacity lead-acid battery suppliers mainly include Shanghai Ding-tiger, Jiangsu Nan-tong, Quanzhou Na-qi, and etc. Shanghai Ding-tiger company is an agent for the world's most famous German HAWKER battery and Japanese GS battery in China. Due to complex imported formalities, expensive import price and limited supply, the domestic research unit can't choose this kind of battery. Domestic battery manufacturers are associated with the mine battery vehicle research unit for the positive cooperation research.

Lithium iron phosphate battery. Lithium iron phosphate battery has many advantages such as high energy density, small volume, light quality, long cycle life, high charge-discharge efficiency, low self-discharge, no memory effect and so on. And due to the negative pressure seal, the battery will not release any toxic polluting gas in the process of charging and discharging. But the disadvantages of lithium iron phosphate battery are its poor safety, explosion danger, complex battery management system. The current domestic large capacity of lithium iron phosphate batteries used in underground battery vehicle is to explore and use. In 2010 national safety standards office issued "Mining flame-proof type lithium ion battery power supply safety technical requirements" and "Mining flame-proof type lithium ion battery power supply safety sign management solution". The file specifies the single lithium iron phosphate battery cannot exceed the nominal capacity of 100 Ah. Monomer battery or battery pack should be placed in separate flame-proof cavity in which anything is not permitted to be placed except battery temperature testing sensor and fuse for shortcircuit. These rules show that the lithium battery is a trend for explosion-proof power source, domestic battery research institutes are engaging in the related technology development. At present, the program for explosion-proof lithium battery whose capacity is $100 \mathrm{Ah}, 128 \mathrm{~V}$ has been listed in National High Technology Research and Development Program (863program) .

\section{Motor Drive Technology}

The main drive modes for underground vehicle are DC motor drive and AC motor drive. Speed control system mainly adopts DC chopper speed regulation system and AC frequency conversion speed regulation system.

DC motor drive technology. The underground battery vehicles widely used DC series motor as drive motor. DC series motor has good performance such as large starting torque, overload ability and other characteristics. The motor's revolving speed will increase while the load torque is increasing. It will work with constant revolving speed in the condition of less than the rated torque and work with constant power in the condition of greater than the rated torque. There are two main 
types of DC motor speed control methods: the primary loop series resistance speed control and DC chopper speed regulation. The series resistance of main loop speed control method is simple, low cost and suitable for rated speed. But in the actual work process, direct current opportunities often work in variable speed running speed ruing state. It causes a large amount of electric energy waste on resistance, high energy consumption, low efficiency, but also can't control speed regulation. DC chopper speed regulation technology based on PWM control technology is widely used in the DC motor speed control system. Compared with series resistance speed control method, this control system is small volume, light quality, high efficiency and good control performance, and can realize infinitely variable speed. So it has been widely used in the field of electric drive. Imported underground vehicle VTC636, 488, VTC650 and domestic CLX3 adopt the technology of DC chopper speed regulation. At present, the domestic motor manufacturers mainly include Henan Nan-yang, Shanxi explosion-proof motor factory, and Yong-ji.

Although DC motor speed regulation technology has got rapid development, the DC motor brushes wear so easily that high maintenance cost is not avoidable. Domestic research units have begun research work of explosion-proof permanent magnet brushless DC motor, which has compact structure, reliable operation, high efficiency, large power density, small volume, long life and other advantages. Currently Tai-yuan institute of CCTEG has cooperated with related motor manufacturers to develop this kind of brushless DC motor of $10 \mathrm{kw}$ and $45 \mathrm{kw}$ and the work has entered the stage of experiment.

AC motor drive technology.Compared with DC motor, AC motor has big power, high efficiency, no brush wear, low maintenance cost and etc. With the emergence of large scale integrated circuit and computer control technology, AC variable frequency speed regulation system arises at the historic moment, its characteristics are large starting torque, high speed control performance, low energy consumption, smooth starting and speed regulation process. As we know, AC system replacing the DC system is a trend in the future in the field of underground battery vehicle. At present, the imported VTC680 underground battery vehicle has adopted AC frequency conversion speed regulation system. In order to solve such problems as high maintenance cost of the original DC motors, domestic research institutes are trying to replace original DC motor speed control system of imported products such as VTC636, VTC650 underground battery vehicle to AC variable frequency speed regulation system. At present, the domestic underground battery vehicles AC motor and its VFDS mainly rely on import.

\section{Conclusions}

"Twelfth five-year" period, our country has to formulate relevant science and technology development planning, will increase in underground vehicle battery technology research, motor drive and control technology research. Along with our country in recent years has made some research achievements in the above technology, underground vehicle battery technology are expected to get breakthrough so as to break the monopoly of foreign technology. From the angle of coal enterprises, the underground battery vehicles in the aspect of energy conservation and emissions reduction reflects the low pollution, zero emissions, low noise, green environmental protection and other advantages are incomparable explosion-proof diesel engine vehicles. And domestic underground battery vehicle costs only half as much as that of the imported similar products in savings for the enterprise purchase cost, shorten the cycle of supply etc. Advantage is obvious. Battery vehicles will has wide application in the coal mine, becoming the main green mining models in the future. 


\section{References}

[1] Yuan Xiao-min, The key technology of coal mine electric trackless transport vehicles, Coal science and technology. Vol. 5 (2011), p. 80-82.

[2] Zhao Lei, Coal mining in electric vehicle drive system is analyzed, Shann-xi Coal. Vol. 6 (2009), p. 55-56.

[3] Sun Fu-que, Modern coal mine auxiliary transportation development trend, Shann-xi Coal. Vol. 3 (2011), p. 15-17. 